$56 \mathrm{O}$ autor expressamente exclui como ajurídicos os elementos metajurídicos em coerência com seu pensamento positivista-marxista.

57 Renner, Karl, op.cit., p.252 "Howe does this change of functions come about? We bave seen that it proceeds steadily, continously, imperceptibly, like the growtb of grass, according to the law of all organic development. As the process of gronetb cannot be understood by a glance at the plant, but only by study of the zerole successive development from germ 10 fruil and again to the nere germ; so the change of furcent "ben only zeben it bas matured".

\section{Bibliografia}

Carbonier, Jean. Sociologia jurídica, Coimbra: Almedina, 1979.

Coelho, Luiz Fernando. Dialética e modelo em Reale. Revista Brasileira de Filosofia São Paulo: nº 132, pp. 397-423, out./nov./dez. 1983.

Czerna, Renato Cizell. A dialética de implicaçăo e polaridade do criticismo ontognoseológico. Revista Brasileira de Filosofia. São Paulo: no 42, pp.243-255, abr./mai./jun. 1961.

Dujovne, Leon - La filosofía del derecho de Hegel a Kelsen, Buenos Aires, Bibliografica Argentina, 1963.

Ferraz Jr., Tércio Sampaio. Algumas observaçōes em torno da cientificidade do direito segundo Migu Reale. Revista Brasileira de Filosofia. São Paulo: $\mathrm{n}^{\circ} 74$, pp. 220-240, abr./mai./jun. 1969

Ferreira, Pinto. O pensamento jurídico-filosófico de Miguel Reale. Revista Brasileira de Filosofia. São Paulo: $\mathrm{n}^{\mathrm{o}} 140$, pp.386-493, out/nov/dez. 1985. riedmann. W. - Legal theory. Stevens e Sons, London, 1960.

Legaz y Lacambra, Luis. Dos libros del professor Miguel Reale. Revisla Brasileira de Filosofia. São Paulo: no 81, pp. 3-8, jan./fev./mar. 1971.

Llorente, Francisco Olmedo. La dialectica de complementariedad en Miguel Reale. Revista Brasileira de Filosofia. São Paulo: $\mathrm{n}^{2} 113$, pp. $27-38$, jan./fev./mar. 1979.

Miguel Reale na UnB: (Conferência e debates de seminário realizado de 9 a 12 de junho de 1981). Brasília: Editora Universidade de Brasilia, 1981.

Reale, Miguel. $O$ direito como experiência. São Paulo: Saraiva, 1968.

Reale, Miguel. Teoria tridimensional do direito. São Pau. lo: Saraiva, 1968

Reale, Miguel. Direito natural/direito positivo. São Paulo: Saraiva, 1984.

Reale, Miguel. Liģốs preliminares de direito. São Paulo Saraiva, 1990.

Reale, Miguel. Teoria do direito e do estado. São Paulo: Saraiva, 1984.

Reale, Miguel. Filosofia do direito. São Paulo: Saraiva, 1990.

Renner. The institutions of private law and tbeir social functions. London: International Library of Sociology and Social Reconstruction, Karl Mannheim, 1949

Strenger, Irineu. Contribuiçào de Miguel Reale à teoria do direito e do estado. Revista Brasileira de Filosofia. São Paulo: no 42, pp. 234-247, abr./mai./jun. 1961.

ieacker, Franz. História do direito privado moderno, Lisboa: Fundação Calouste-Gulbenkian, 1980.

\title{
As cartas de intenção no processo formativo da contratação internacional: os graus de eficácia dos contratos e a responsabilidade pré-negocial
}

Trabalho apresentado no seminário sobre "Contratos Internacionais e Mercosul", .

Judith Martins-Costa

Professora de Direito Civil na Faculdade de Direito da UFRGS.

SUMÁRIO

Introdução. I) As Condições Necessárias ao Estabelecimento de Vinculação Jurídica Negocial e Pré-Negocial: a) As Categorias Jurídicas da Proposta e da Aceitaçāo; b) A Relação Jurídica Estabelecida Mediante a Troca de Cartas ge Intenção: II) Os Efeitos Decorrentes da Vinculacão Estabelecida Mediante a Troca de "Cartas de intenção" a) Cartas de Intenção e Efićácia de Primeiro Grau; b) A Configuração da Responsabilidade Pré-Negocial pela Ruptura Injustificada das Tratativas. Conclusão.

\section{Abstract}

Les relations internationales génèrent, actuellement, l'expansion de types et de formes de liens intersubjectifs assez divers par rapport à ceux qui, d'une façon traditionnelle, on désigne "contrat". Aux contrats internationaux précède, ba bituellement, une période pré-contractuelle où les futurs contractants échangent des documents et se donnent des lettres où sont établis certains points d'accord qui devront être postérieurement ratifiés. Pour les contrats internationaux on ut lise, dans cette phase pré-contractuelle, certaines figures juridiques, entre autres les "lettres d'intention", documents destinés à fixer les bases contractuelles avant l'établissement du conten contractuel intégral. La question qui se pose est donc, de déterminer si les "lettres d'intention" générent - et, si génerent, sous quel fondément des liens juriques d'obligation entre les parties, vue la distinction entre ces lettres et le pré-con trat. Cet étude se divise, ainsi, em deux parties. dans la première on analyse les conditions néces saires à l'etablissement des liens juridiques con tractuels; dans la deuxiéme, en s'appuyant sur le droit comparé, on examine les effects $d u$ lien établi travers le changement de lettres d'intention.
Introdução

Quem observar o que ocorre atualmente na prática do comercio internacional perceberá a expansão de tipos e formas vincula tivas em tudo e por tudo diversas daqueles que poderiam ser agrupados sob o conceito tradicional de contrato - tal como advindo este, do modelo posto pela Codificação do século XIX - ao ponto de a doutrina apontar à visualização de uma nova lex mercatoria ${ }^{1}$ a conformar regras e a criar modelos jurídicos à margem do direito posto pelo Estado.

Por estas razões, o exame dos contratos internacionais não pode restar reduzido como quer certa doutrina, apenas aos pontos tradicionalmente demarcados pela disciplina do Direito Internacional Privado, vale dizer, a sua relação à determinada ordem jurídica estatal ou interestatal ou ao critério meramente formal ou externo da internacionalidade. Isto porque, no quadro atualmente delineado, os contratos internacionais não se alocam apenas como relações de intercâmbio fundamentadas numa determinada noção de contrato que não é mais do que a de um contrato comum afetado pelo problema da estraneidade - exame para qual bastaria determinar qual a lei aplicável 
à sua regência ${ }^{2}$ - colocando, ao contrário, problemas de natureza mais complexa.

Com efeito, a análise do contrato internacional, em especial a de seu processo for mativo, a partir de uma perspectiva excludente teria o defeito de - a par de descurar o exame dos aspectos substanciais do vínculo contratual operado em escala internacional - sobrevoar os dados, já por si complexos, da internacionalização econômica, jurídica e ideológica, de ignorar as singularidades do instável meio ambiente onde alocados tais ajustes, de esquecer a originalidade de seu próprio objeto - o qual abrange o vastíssimo campo das operações de troca, de concessão de financiamentos, do intercâmbio tecnológico, dos serviços e da produção - $\mathrm{e}$, bem assim, as peculiaridades de suas partes - além dos simples particulares, os Estados, entidades públicas, grupos multinacionais, empresas bi ou multinacionais ${ }^{3}$.

As questões aí envolvidas, para além do campo específico do Direito Internacional Privado ou do Direito dos Negócios propõem à Teoria Geral do Direito Privado renovadas indagações acerca do que se convencionou chamar de teoria das fontes, porquanto conduzem à constatação da formação, em muitos casos, de vinculaşão jurídica cuja gênese ancora em direitos de formação não-estatal e de moldura não - ou ainda não - positivada.

Sabe-se que pelos menos uma (e talvez a principal) razão do desenvolvimento de tais figuras radica na necessidade, constatada agudamente ns relações internacionais, de ser mitigada a excessiva presença do Estado legislador, de modo a permitir a regulamentação autônoma das atividades econômicas privadas. A dinamização na escolha de soluçōes adequadas ao enfrentamento das questões postas diariamente pela prática dos negócios ditaria, por isso mesmo, as novas normas que se formam paralelamente às regras do corpus legislado em cada ordem estatal e mesmo das normas supranacionais.

No âmbito do direito dos contratos, como em nenhum outro, se percebe, portanto, uma nova realidade cuja análise requer a referência, ainda que preliminar, a alguns dos postulados advindos da teoria geral das fontes do negócio jurídico como marcos fixadores do instituto.

Tradicionalmente se tem por assente que os contratos - espécie por excelência do gênero negócio jurídico - se formam pelo encontro de duas declarações de vontade, uma que oferta, outra que aceita, ambas definidas sobre os "elementos" do negócio, as quais, expressando consentimento, se entrosam e entram no mundo jurídico de forma imediata ${ }^{4}$.

Esse esquema, facilmente caracterizado quando se trata das simples relações de troca, cotidianamente operadas, se mostrará todavia menos claro nas ocasiões em que o objeto de exame constituir uma relação jurídica que não suceda, abruptamente, ao nada jurídico, vale dizer, nas situações em que à conclusão do negócio anteceder uma longa fase preparatória ${ }^{5}$ ou um complexo processo genético ${ }^{6}$, como comumente ocorre na negociação internacional.

$\mathrm{O}$ que significa este período preparatório, habitualmente complexo, onde as partes, desejando futuramente contratar, trocam cartas, emitem telex, telefax, telefonemas, estabelecem previamente pontos parciais do acordo serem posteriormente ratificados? Estará tal período submerso no limbo de não-Direito de que tratam os sociólogos?

Assinala com pertinência Guido Alpa que os vínculos estabelecidos nessa fase, alocados "antes" ou "ao lado" dos contratos propriamente ditos, se inserem na tendência, observada nas relações comerciais, de conferir valor jurídico aos chamados contatos - tratativas, protocolos, pourparlers, negociações preliminares, instructions to proceed, cartas de intenção, gentlemen's agreement 'e outros - figuras ou meios de viabilização da circulação econômica de bens que têm como efeito, para o que aqui concerne, o aumento de deveres a cargo dos envolvidos o conseqüente estabelecimento, pari passu, de novos tipos de garantias ${ }^{7}$

Aos juristas, além do exame dos motivos de tal fenômeno, se põe a questão de saber se essas novas figuras conduzem a uma verdadeira vinculaşa jurídica, mesmo que ainda em estado embrionário ${ }^{8}$, dotadas, portanto, da eficácia e coercibilidade próprias à instância do mundo jurídico ou se os seus efeitos estão, ao contrário, confinados tão-somente ao universo dos princípios morais, das promessas sem valor jurídico para as quais a violaşão não conduz necessariamente à sanşão?.

Por isto mesmo, nos diferentes sistemas jurídicos se observa atualmente, a par da extrema atenção, a fase que precede à conclusão do contrato e aos diferentes meios encontrados para garantir as obrigações assumidas, o debate acerca dos diferentes graus de eficácia dessas figuras.

A questão subjacente ao presente estudo consiste, pois, na fixação do momento em que se verifica a vinculação jurídica de índole obrigacional, discernindo-a daquela ca-

racterizadamente negocial. Do seu estabelecimento defluirá, por consequiencia, o exame dos efeitos decorrentes da vinculação estabelecida no período preparatório ou antecedente à formação do vínculo contratual no âmbito dos negócios internacionais, exam nando-se aí a responsabilidade pré-negocial.

\section{I) As condições necessárias ao estabelecimento de vinculação jurídica negocial e pré-negocial}

Se o contrato é, segundo repetida lição, o acordo entre duas ou mais declarações de vontade, opostas e convergentes, para a produção de efeitos jurídicos ${ }^{10}$, será possível afirmar a existência de efeitos jurídicos antes de existir contrato?

Para a resposta a esta indagação será necessário saber como atualmente a doutrina e a jurisprudência tratam a questão, isto é, se consideram - como os juristas do ius commune e os praxistas do século XVII - que as promessas e os tratos anteriores à conclu-

$\mathrm{Y}_{\text {são do acordo são meros pacta nuda, despro- }}^{\text {as }}$ vidos de ação ${ }^{11}$ - ou se, superando tal entendimento, admitem o reconhecimento de certos degraus de eficácia ainda enquanto o negócio não se concluiu. Será conveniente, para tanto, referir brevemente os pressupostos da vinculação negocial (a) para exami- nar, após, a natureza da relação que decorre das tratativas, em especial da troca de cartas de intenção (b).

(a)) As Categorias da Proposta e da Aceitação

Não se discute que, nos negócios jurídicos há, sempre, manifestação ou declaração de vontade, por vezes considerada "elemento" do negócio ${ }^{12}$, por vezes tida como sua "gênese ${ }^{13 "}$ ", sendo habitualmente sublinhado o seu papel no que concerne à distinção entre os negócios jurídicos em geral e os demais atos jurídicos do tipo principal de negócio - o contrato - cujo conteúdo se tem como fixado precisamente por ela ${ }^{14}$.

É também consabido que, quando essa declaração de vontade deve dirigir-se a alguém, que a recebe, diz-se vontade receptícia, elemento "recepção" sendo essencial à $e f i$ cácia da declaração porque é justamente o que vai "colar" no negócio as duas declarações - a que oferece, ou propõe, e a que aceita ${ }^{15}$, de modo que é pela proposta que a vontade alcança o outro pólo da relação jurídica. Por isso, aliás, bem critica Pontes de Miranda os que afirmam que, pelo fato de a proposta poder não ser aceita - perdendo então a eficácia - não constitui, a mesma, negócio jurídico: pelo contrário, esclarece, mesmo antes da aceitação, a oferta válida entra no mundo jurídico, tanto que pode ser revogada ${ }^{16}$

Todavia, como a formação do negócio jurídico exige que as duas declarações de vontade se soldem, bilaterizando a relação, os efeitos jurídicos se operam nas duas esferas: quem aceita também exprime vontade, uma e outra devendo ser convergentes quanto aos efeitos buscados. Daí porque no suporte fático do negócio jurídico bilateral dever haver a coincidência de vontades: esta correndo, o ato existindo e sendo válido o negócio bilateral se forma e entra no mundo jurídico ocorrendo precisamente neste momento a vinculaşão negocial que dá vida ao contrato ${ }^{17}$. A aceitação jurídica é, pois, ato que, encontrando a oferta, por a ela corresponder, tem por efeito dar nascimento ao contrato. 
Diversamente, se se tratar de proposição a que falte tal suscetibilidade de ser aceita ${ }^{18}$ não há proposta no sentido jurídico. Assim, se alguém propõe a aquisição de um bem mas omite a referência ao preço a pagar, não há, rigorosamente, "oferta". Poderá a estar configurado um trato ou uma "proposta a receber proposta". Todavia, embora não se configure, nesse estágio, vinculaşão contra tual, remanesce ainda parte da questão pre liminarmente posta: as proposições realizadas por figurantes de um futuro contrato conduzem, ou não, a certo tipo de vincula ৎ̧ão jurídica?

Do extenso rol das figuras habitualmente utilizadas na fase preparatória no comércio internacional, se observará, através do exame das cartas de intengãa a ocorrência, ou não, do vínculo.

b) A relaşão jurídica de trato estabelecida mediante a troca de cartas de intenção

As dificuldades que se põem no mundo dos negócios internacionais à conclusão de um contrato ${ }^{19}$ decorrem dos mais variados fatores: as oscilações cambiais, a modificação, por vezes brusca, nas políticas nacionais, vicissitudes de ordem estritamente política - interna e externamente consideradas lítica - interna e externamente consideradas
- fatores econômicos os mais diversos, constituem óbices para cuja superação as partes de valem, no período da negociação, da troca de correspondência ${ }^{20}$ mediante a qual vão concertando, paulatinamente, o futuro negócio. Em especial as relaçōes comerciais operadas em espaço político não-homogêneo, e em presença de uma ordem jurídica e econômica não-unitária, requerem dos juristas e negociadores um grande esforço de consolidação dos pontos já acordados ou em vias de acordo e, portanto, o período da negociação é marcado pela redação e troca de documentos onde é necessário demarcar com precisão a significaşão e o valor jurídico de tais documentos, para evitar conflitos futuros.

No entanto, nem sempre tal precisão se verifica. A expressão "cartas de intenção" ou "cartas de princípios" denota uma variada tos de um e de outro serão completamente diversos, mas, em grande parte dos casos, só o exame da situação concreta permitirá a correta qualificação.

Em linhas gerais, é possivel afirmar que as cartas de intenção não constituem, em regra, obrigação de fazer, de concluir contrato. Tanto é assim que habitualmente se fazem acompanhar da expressão "sem compromisso" ou "sujeito a confirmação". Nestas circunstâncias não bá proposta no sentido jurídico, porque no suporte fático não entra a vontade de produzir efeito de vinculaşão, devendo, contudo, a qualificação jurídica adequada ser aferida após o exame punctual dos termos do documento, porquanto se definidos res, pretium e condictiones poderá configurar-se o contrato, ex vi dos artigos 191 do Código Comercial Brasileiro e 639 do Código de Processo Civil: nessa matéria, como bem afirmou o Ministro José Carlos Moreira Alves em acórdão conhecido, de pouco importa o nomem juris dado pelas partes - simples minuta, carta de intenções ou carta de princípios - na medida em que se se passa uma minuta completa sobre todos os pontos do contrato, ao menos sobre todos os pontos principais, podendo os outros ser supridos por disposiçôes legais, $e$ as partes a aprovam, e se, de acordo com a lei ou a vontade das partes não tenba que ser dado ao contrato forma ad solenitatem, firma-se entre eles vínculo obrigatório ${ }^{27}$.

Como se pode observar, a grande dificuldade está em verificar se a carta de intenção, por seu texto, exprime a intenção de concluir contrato ou se o seu conteúdo já é bastante para formá-lo.

Alguns sistemas jurídicos, como o inglês, contêm regra no sentido de que prevalece, sempre, a vontade das partes, de maneira que, consignado no acordo que o mesmo não tem efeito obrigacional, os Tribunais hesitam em reconhecer um poder de obrigar que as próprias partes não reconheceram. Todavia, embora a intenção de criar vinculação jurídica dependa da vontade das partes em admitir ou excluir o caráter obrigacional das afirmações trocadas, pode a mesma restar deduzida da "suficiência objetiva" do acordo concluído, desde que o mes- mo seja completo (ou "suficientemente" completo), digno de ser protegido e "suficientemente inteligível ${ }^{28}$.

Assim ocorreu num caso judicial considerado verdadeiro leading case, o já clássico acórdão proferido no caso Rose and Frank versus Crompton Bros, de 1923: os demandantes, ingleses, haviam firmado com os demandados, norte-americanos, um acordo por carta, pelo qual os ingleses enviariam à América estoques de papel pintado. No acordo, denominado intent letter, estatuía-se que as partes não pretendiam, de forma alguma, vincular-se juridicamente. Todavia em decorrência da carta, foram enviadas três remessas de papel, que os norte-americanos retiraram do porto e venderam aos seus clientes. Instados a pagar, refugiaram-se na cláusula do acordo que o declarava não-obrigatório. Decidiu o Tribunal que, na espécie, uma ordem executada constituía um perfeito contrato de venda, reconhecendo efeitos contratuais ${ }^{29}$.

No direito norte-americano, diferentemente, os Tribunais controlam a intenção das partes ${ }^{30}$ : se estas excluem a intenção de criar vínculos contratuais, os juízes respeitam essa intenção. É que é incisiva, naquele país, a fórmula de que o contrato é uma operação de self-government, fórmula esta indicativa da consideração da iniciativa contratual como um instrumento de tráfico de riqueza em função do livre jogo da autonomia privada - freedom of contract -, ao qual corresponde uma carga de riscos em princípio infensa aos mecanismos de redistribuição dos riscos.

Como conseqüência, as partes podem romper as tratativas sem restarem submetidas a um juízo de responsabilidade pelos danos eventualmente causados pelo rompimento ${ }^{31}$. Inadimite-se contudo, pelas regras da equity, um comportamento contrário aos próprios atos. Neste particular as regras da estoppel, embora constituam regras de prova, alcançam a proteção da confiança na declaração de vontade: o declarante resta estopped. por uma presunção absoluta, para impug nar as declaraçōes inequívocas que decidiram a outra parte a concluir o contrato ${ }^{32}$. 
$\mathrm{Na}$ venda internacional de mercadorias (bens-móveis), alguns traços do sistema civilista contagiam essa matéria. A Convenção adota, por exemplo, o sistema civilista da oferta e não utiliza a noção de consideration como critério do caráter executório da proposição de contratar ${ }^{33}$, restando afasta$\mathrm{da}$, pois, neste particular, uma peculiaridade do sistema da common law em matéria contratual ${ }^{34}$.

Observa-se, pois, que nas relações comerciais, de forma especial naquelas operadas a nível internacional, o formalismo e a fechada definição de "tipos" jurídicos constituem espécimes em extinção ${ }^{35}$. O renascimento da lex mercatoria, por seu turno, conduz a uma série de debates ancorados em razões de fundo político, na medida em que a recusa ao chamamento das regras seguras do direito estatal poderia conduzir ao predomínio da "lei das multinacionais". Todavia, bem observa Bruno Oppetit, que, se não mitificada também a lex mercatoria, isto é, se não for considerada ela própria um sistema jurídico completo, suficiente per si, absorvente dos princípios do direito internacional privado e se, ao contrário, for a mesma alocada em seu próprio terreno que é o da juridicidade e o da teoria das fontes do direito - não haverá porque considerá-la sob a perspectiva de um positivismo estatal ultradogmático: neste campo, perspectiva do pluralismo jurídico tem um importante papel a desempenhar, de modo que o processo formativo da contratação internacional obedecerá aos usos ${ }^{36}$ cuja realidade é atestada pelos práticos e pelas autoridades, corporativas ou jurisdicionais, do comércio internacional e, inclusive, do Estados envolvido ${ }^{37}$

Os usos comerciais em vigor atestam, em paralelo, ao fenômeno do declínio do formalismo, a planificação progressiva das re laçōes contratuais fundadas no dever de agi com boa-fe e correşa $o^{38}$, o qual constitui prin cípio jurídico fundamental, esteja posto de forma explícita ou implícita nos ordenamentos ${ }^{39}$. Em matéria de venda internacional de bens móveis, a própria Convenção de Viena contém diretiva de interpretação que remete diretamente ao standard do comportamento conforme à boa-fé ${ }^{40}$

É justamente o princípio da boa-fé, perspectivado em sua feição objetiva, como convém ao campo das relações de direito obrigacional que, em certas hipóteses, imporá às partes que pretendem concluir contrato - $e$, por isso desenvolvem tratativas - uma série de deveres situados ainda no campo pré-negocial. Para assinalar tais deveres, parece relevante examinar, inicialmente, os feitos jurídicos que possam decorrer da troca de cartas de intenção.

II) Os efeitos decorrentes da vinculação estabelecida mediante a troca de cartas de intenção

Dos diferentes planos através dos quais Dodem ser examinados os atos jurídicos podem ser examinados o mente este último pode ser mensurado por graus. Há, portanto, eficácia plena, que diz respeito à integralidade dos efeitos decorrentes de um negócio jurídico ${ }^{41}$ e uma eficácia de primeiro grau ${ }^{42}$, que surge mesmo se o negócio enquanto tal não se concluiu.

Essa produção de efeitos parciais não deriva da vontade humana mas encontra fundamento na incidência de princípios jurídicos de valor, considerados fundamentais. No direito das obrigaçōes, tais efeitos decorrerão em especial da incidência do princípio da boa-fé, em atenção à tutela da confiança, de onde decorrem os deveres de agir com lealdade e de respeito aos usos do tráfico jurídico. Serão examinados, portan to, à luz deste princípio, os efeitos que decorrem do fato da dação de cartas de intenção (a) e os casos em que a interrupção das tratativas negociais pode resultar em responsabilidade civil (b).

\section{a) Cartas de intenção e eficácia de} primeiro grau

Inspirada em fontes e elementos alcançados pela Sociologia, vem a melhor doutrina procurando desenhar fattispecie o mais pos- sível abrangente no que concerne ao fenô meno do nascimento de direitos e deveres, de modo a situar ponto geral suscetível de englobar unitariamente os efeitos de direito e suas fontes: daí decorre a proposição $d$ categoria dogmática do contato social ${ }^{43}$, a qual adota, como ponto de referência, as categoria sociológicas da proximidade e da distância tratadas na Teoria da Associação - para, me diante o escalonamento os graus de contato que se formam na vida social, mensurar os efeitos de direito decorrentes desse contato.

Segundo tal teoria, o contato mais distante é o mero fato de viver em sociedade em "associação". O grau mais próximo justamente o contrato, forma voluntária, qua lificada do contato social ${ }^{44}$. Entre esses dois pontos se verifica uma série de graus intermediários de contato, ocorrendo entre todos os graus, uma certa unidade, geradora de efeitos também, e proporcionalmente, mensuráveis por graus, os quais se refletem no iter formativo da relação jurídica obrigacional. Para que esta se crie e se desenvolva, as pessoas entram em contato, vale dizer, $\mathrm{s}$ relacionam e, na medida em que esta relação é reconhecida pelo direito, se transforma em relação jurídica, esteja em sua base atos jurídicos lícitos ou atos ilícitos ou simples fato de se estabelecer a relação.

$\mathrm{O}$ "contato" mantido na fase pré-negocial dá lugar à formação de um vínculo que não é igual àquele decorrente do simples fato de viver em sociedade. Como bem re fere Mota Pinto, "entrando em negociafóes, sai-se do círculo dos deveres gerais bumanos para penetrar no mundo dos direitos relativos ${ }^{45 "}$. Entra-se, portanto, no espaço das relações obrigacionais uma vez considerado que, "ao lado das obrigafões que entroncam numa vontade real de certos efeitos (negócio jurídico), ou numa vontade normal (quase negócio jurídico), ou que resultam dum facto ilícito, outras bá, que a lei estabelece para a tutela de interesses públicos relevantes sem curar da intenşão dos particula $r^{46}{ }^{46}$. Justamente aí se aloca a proteşão da confiansa de cada uma das partes nas proposicões da outra, a qual resta situada como "subs tracto teleológico da eficácia ex lege ${ }^{47} . "$
Como se observa tais relações, não sendo idênticas aquelas que defluem do simples fato de viver em sociedade, também não o são tipicamente negociais, porque a ordem jurídica poderá prescindir de considerações acerca da volição dos particulares. Constituem, pois, "relações contratuais fáticas" ou "atos existenciais ${ }^{48 ",}$ os quais podem restar caracterizados em período anterior ou mesmo indepente da celebração de qualquer negócio jurídico, como ocorre no caso da responsabilidade pré-negocia $1^{49}$.

Como é intuitivo, tal concepção se vincula à visualização da relação obrigacional como um processo, um suceder de fases ou planos polarizado pelo adimplemento ${ }^{50}$, um vínculo dinâmico, portanto, que não se esgota na mera soma de suas obrigações principais - o crédito e o débito - mas que se expande inclusive às fases prévias à avença e pós-extintiva, em razão, particularmente, da incidência do princípio da boa-fé objetiva em tanto que matriz de deveres de conduta que atingem ambos os partícipes da relaçãa ${ }^{51}$.

Nesta perspectiva, muito embora a troca de cartas de intenção não gere vinculação negocial - porquanto ainda aí não configuradas proposta e aceitação - podem, as mesmas, restarem situadas como fontes de vinculação jurídica obrigacional, gerando, portanto, deveres ${ }^{52}$ e responsabilidades: somente quando se têm presentes a concepção dinâmica da relação obrigacional e a força da incidência do princípio da boa-fé objetiva será possível compreender a relevância para a dogmática obrigacional, da noção de contato social como fonte genérica de deveres que se alocam nos planos pré e pós-obrigacional ${ }^{53}$.

Entre os deveres que defluem do princípio da boa-fé objetiva, está o da manutenção de um comportamento leal e coerente - o que implica a aplicação da máxima - venire contra factum proprium - o de informar com correção e a rejeição do abuso de direito, implicando a boa-fé objetiva cabal limitação do exercício de direitos abusivos, os quais, entre nós, contrariam inclusive o va- 
lor maior da solidariedade da vida social (Constituição Federal, art. 3ㅇ, I)

$\mathrm{Na}$ fase prévia à da efetiva constituição da avença a boa-fé fundamentará o instituto da responsabilidade pré-negocial - feição atual da antiga teoria da culpa in contrabendo ${ }^{54}$ campo de particular relevância nos contratos internacionais em razão, justamente, do longo processo formativo que costuma caracterizar tais negócios: a ruptura das tratativas, consubstanciadas mediante a troca de cartas de intenção e acordos preliminares, pode conduzir ao dever de indenizar o participante das negociações pelas despesas realizadas em função da expectativa legítima em concluir o contrato. Do mesmo modo conduzirá ao dever ressarcitório o fato de um dos partícipes da relação pré-negocial não informar com correção sobre pontos relevantes à conclusão do futuro contrato.

\section{b) $A$ Configurafãa da Responsabilidade} Pré-Negocial

Como assinala Marina Arietti ao indica os mais valiosos estudos produzidos na Itália, França e Alemanha nos últimos dez anos acerca da responsabilidade pré-contratual ou pré-negocial, o período que vai do início da década de 80 aos nossos dias se caracteriza por um renovado interesse da matéria ${ }^{55}$ tratada pioneiramente por Jhering em ensaio célebre ${ }^{56}$. Hoje se compreende que o instituto tem um alargado campo ${ }^{57}$, estendendo-se a responsabilidade para além da hipótese do dever de declarar as causas de invalidade do futuro contrato ${ }^{58}$, para abranger, também, danos decorrentes do processo formativo por infringência aos de veres de comunicaşão ou informaşão, de custodia, de segredo e os de conservasáa $0^{59}$ e ainda as situações em que não se tenha celebrado nenhum negócio por ruptura da fase negociatória ou decisória ${ }^{60}$.

Com efeito, em tema de recesso na fase das tratativas negociais constitui, na Itália "opinião generalizada que do dever pré-contra tual de boa-fe decorre a obrigaşão de não interromper as negociacões preliminares sem justa causa $^{61 "}$, firmando-se a jurisprudência no sentido de que, para surgir a responsabilidade pré-negocial, é necessário a razoável confiança da parte - isto é, do participante nas tratativas - na futura conclusão do contrato, a ausência de um justificado motivo para a ruptura e o dano decorrente da inpara a ter 0 seu qualificativo averiguado sempre nas concretas circunstâncias do caso ${ }^{63}$.

A questão da indenizabilidade do dano decorrente da interrupção das tratativas coloca importante tema de reflexão que adentra o campo da política do direito, e que é o de saber até que ponto o princípio da autonomia ou liberdade contratual - que justificaria a decisão de não contratar, isto é, de interromper as tratativas - estaria sendo ferido. Argumenta-se, em favor da indenizabilidade do dano, que a garantia de um indiscriminado poder de interromper as tratativas acabaria por privilegiar os que operam no mercado de modo desleal ou pouco racional $l^{64}$, questão que se coloca com particular agudeza no mercado internacional em razão de suas implicações políticas, para além das econômicas. No entanto, o exercício da liberdade que se traduz na ruptura das tratativas pode, efetivamente, causar dano ao partícipe por privá-lo de ganhos legitimamente esperados, ocasionando, ain da, o prejuízo pelas despesas já realizadas em função do futuro contrato, o que conduz diretamente à violação da justiça subs tancial.

Hoje se sustenta, em oposição ao modelo restritivo dos códigos oitocentistas, a conveniência da utilização de expressões - ditas "cláusulas gerais ${ }^{65}$ - onde se possa considerar admitida a garantia da boa-fé objetiva dos futuros contraentes na fase ante-negocial ${ }^{66}$ : as codificações mais recentes, tais como o já citado Código Italiano (art. 1337 e 1338), o Código Civil Português (art. 227, no 1), o Código Grego (arts. 197 e 198) e o Projeto de Código Civil Brasileiro (arts. 421 e 422) incluem tais disposições ${ }^{67}$.

Por isso, nos diferentes sistemas jurídi cos observa se a intervenção do direito na relação pré-negocial a fim de salvaguardar a harmonia entre o princípio da liberdade e o da tutela da confiança legítima ${ }^{68}$. Mesmo na ausência de regras codificadas, cada ordenamento exprime semelhantes linhas de tendência $^{69}$ às quais subjaz a consideração que o controle das tratativas, baseado na tutela da confiança e dos deveres de comportamento que integram a disciplina normativa considerada em suas finalidades, se impõe à verdadeira "mística" da autonomia privada segundo a qual o rompimento das negociações não constituiria mais do que o exercício de direito potestativo não sindicável pela autoridade pública ${ }^{70}$.

Mesmo na tradição da common law, onde vige com acentuada força, como acima visto, a fórmula do self-government em matéria contratual, certas regras, fundadas no dever de negociar in good faith conduzem a resultados semelhantes aos alcançados nos sistemas civilísticos pela doutrina da culpa in contrabendo. Em trabalho famoso, Friederich Kessler e Edith Fine demonstraram como as noções de boa-fé e os usos do tráfico leal ("good faith and fair dealing") afetam as negociações preliminares através das doutrinas da negligence, estoppel e da implied contract $^{71}$. Estudos mais recentes têm se ocupado especificamente da questão da precontractual liabiality no direito norte-americano e discutido as suas bases, seja nas teorias do injustificado enriquecimento (unjust enrichment), erro na representação (misrepresentation), promessa específica (specific promise) seja na existência de um dever ou de uma obrigação geral de conduta (general obligation) fundada na boa-fé, como consta especificamente de regras postas no American Uniform Commercial Code e do Restatement (Second) of Contracts ${ }^{72}$

Similar panorama pode ser observado na Inglaterra, onde as normas referentes à responsabilidade pré-negocial resultam da confluência de regras de common law, equity e dos statutes. Mesmo em caráter excepcional, aceita-se, em determinadas circunstâncias, a configuração da responsabilidade ainda que às negociações não tenha se seguido o contrato $^{73}$

Foi, no entanto, nos sistemas civilísticos que a doutrina melhor se desenvolveu. No
Código Civil Alemão inexiste norma simiar à do citado art. 1337 do Código italiano. Mesmo assim, certas regras de direito obrigacional dão suporte ao desenvolvimento de um amplo quadro de responsabilidade pré-negocial $^{74}$, deduzindo a jurisprudência uma "relação obrigacional autônoma", complementar ao direito escrito, que decorre da "forga compromissadora do contato social, de uma responsabilidade por confianca iludida, ou de uma relaşão obrigacional sem obrigaşão primária de prestaça a ${ }^{75 "}$. Isto porque considera-se que, em matéria de direito de dano, é imprescindível o "exame dos fins do complexo normativo da lei ${ }^{76 "}$

Por estes caminhos, embora não reconheça o BGB uma proposição jurídica genérica no sentido de que a mera entabulação de relações contratuais fundamente obrigações de proteção em favor do parceiro das negociações, se admite que "mesmo sem uma base legal positiva é de reconbecer-se $q u e$, segundo a boa-fé, o parceiro contratual, também antes da celebração do contrato, tem uma posigão diferente daquela do quivis ex populo, cujos bens jurídicos os parágrafos 823 $e$ ss. protegem ${ }^{77 "}$. A natureza da responsabilidade é, contudo, considerada contratual porquanto assim se pretende conferir maior garantia ao lesado, - embora boa parte da doutrina venha acenando à configuração de um terceiro gênero de responsabilidade, independente dos dois gêneros tradicionais.

$\mathrm{Na}$ França, carente o Código Civil de norma com a amplitude da cláusula gera contida no artigo 1337 do Código Civil Italiano ${ }^{78}$ a ruptura injustificada das negociações ocasiona, ainda assim, responsabilidade civil indenizável sob a forma da responsabilidade delitual, podendo o dano ser caracterizado, inclusive, pela perda de uma chance, vale dizer, pela perda de outras oćasiões de concluir contratos similares ou complementares ou pela não-realização dos benefícios que haviam sido procurados no contrato não realizado ${ }^{79}$.

No sistema do Código Civil português tais casos são regulados, também sob a for ma da responsabilidade delitual, pelo artigo 227, explicitamente fundado, como se viu, 
no dever de agir segundo a boa-fé $\mathrm{e}^{80}$ aplicando-se a esta responsabilidade, na forma do artigo 45, a lei do Estado de onde decorreu a principal atividade causadora do prejuízo ou, em caso de responsabilidade por omissão, a lei do lugar onde o responsável deveria ter agido. $\mathrm{Na}$ hipótese de a lei do país onde ocorreu a atividade não o considera responsável, e assim considerar a lei do Estado onde produzido o efeito lesivo, est última será então a aplicável (art. 45 , segunda alínea).

O fundamento das regras postas no Có digo português reside nos cânones da leal dade e probidade, tutelando-se "diretamente a fundada confianga de cada uma das partes que a outra conduza as negociafóes segundo boa-fe $e^{81}$, considerando-se, para tal que "o alicerce teleológico desta disciplina ultrapassa a mera considerasãa dos interesses particulares em causa" porquanto "avulta, com especial evidên cia, a preocupasão de defesa dos valores sociais e da facilidade do comércio jurídico ${ }^{82 "}$.

$\mathrm{Na}$ Argentina, a vigente redação do art. 1.198 do Código Civil permite concluir pelo acolhimento expresso do princípio d boa-fé. Tanto é assim que decisão de 1986 da Camara Nacional de $1^{\circ}$ Civel, de Buenos Aires sustenta que "a boa-fé, princípio superior e geral de todo o ordenamento social e jurídico organizado, deve alocar-se como valor funda mental na bierarquia dos valores jurídicos" (d modo que) "essa diretiva impõe aos sujeitos o dever de proceder, tanto no desenvolvimento das relaşóes jurídicas como na celebraşão, interpreta §ãa e execuşão dos negócios jurídicos, com retidão e bonradez ${ }^{83}$.

Assinala, neste particular, Carlos Alberto Ghersi que este artigo, juntamente com o artigo 902 do mesmo Código, constituem normas que permitem ao jurista analisar conduta das partes antes, durante e depois do acontecimento dos atos ou fatos jurídicos das relações emanadas, assim como as cir cunstâncias fáticas que os rodearam ${ }^{84}$. Um das conseqüências da incidência do princípio na relação obrigacional perspectivada como um processo - perspectiva também acolhida doutrinariamente naquele sistem jurídico ${ }^{85}$ - está, justamente, em que "na retirada intempestiva dos tratos preparatórios ou a formasão de qualquer ato jurídico, a parte (oferta) ou as partes (preliminares do contrato) devem conduzir-se com a diligência e a consideraşão que é de ser esperada segundo a boa-fé que deve reinar nas negociafóoes ${ }^{86}$.

No sistema do direito comum brasileiro a responsabilidade pré-negocial segue, como na maioria dos sistemas jurídicos, o modelo da responsabilidade delitual. Embora não especificamente regulada no Código $\mathrm{Civi}^{87}$ entende-se que o instituto encontra ampla guarida na cláusula geral do art. 159 do Código Civi ${ }^{88}$, indenizando-se os gastos feitos para a realização do negócio ${ }^{89}$.

Contudo, para além da discussão acerca da natureza da responsabilidade - se constiuiria, ou não, um tertium genus ao lado da responsabilidade contratual e da extracontratual - o certo é que, entre nós, não se pode falar em "responsabilidade derivada de esão a contrato" se ainda não se formou 0 contrato. Por igual não se deve imaginar uma suposta "pré-eficácia" do contrato, pois este ou se concluiu pela colagem das declarações de vontade negocial ou não se concluiu: o que há, na fase das tratativas, relaşão jurídica de trato e o dever jurídico conectado à responsabilidade - é o dever de agir conforme a boa-fé, o qual decorre da jurisdização de valores éticos incorporados pelo ordenamento em matéria obrigacional.

\section{Conclusão}

No universo das relações comerciais, qual se espraia em uma economia fundada no crédito, onde a moeda é um valor marcado pela instabilidade e as regras econômicas se interacionam diretamente com as vicissitudes da ordem política a atuação do que se envolvem em negociaçōes visando a contratar, requer o estabelecimento de um padrão mínimo de previsão e segurança que permita a planificação das operações negociais.

A feição hoje requerida à teoria das fontes das obrigações e o reconhecimento do efeitos de direito que decorrem do vínculo obrigacional se encontram, em inúmeras si- tuações, constrangidos pelas ultrapassadas amarras de um modelo proposto e construído para a utilidade de uma organização social em tudo e por tudo diversa da nossa: o século XIX, onde finalizada a elaboração dos grandes modelos jurídicos incorporados pelos códigos foi marcado pela riqueza fundada na propriedade imobiliária, pela nacionalização da economia, pela estabilidade da moeda e pela quase intransponível cisão entre Estado e Sociedade, Direito e Moral. Mostra-se, por isso, mais do que conveniente o endosso à doutrina dos mais diferentes países que vem propondo o deslocamento do eixo central da teoria das obrigações da tutela da vontade à tutela da confiança.

A par das singularidades contidas nos diferentes ordenamentos nacionais e mesmo para além das convenções que estabele$\mathrm{cem}$, em certos setores, regras uniformes, observa-se a tendência à unificação de soluģóes jurídicas, ao menos no que concerne ao aspecto substancial dos problemas postos. Tal tendência não se deve ao acaso, e as coincidências existentes podem ser creditadas à existência de circunstâncias sociais e culturais assemelhadas: muitas vezes as práticas e as soluçöes são comuns, não obstante discrepancia discrepancia entre os conceitos e figura dogmáticas nacionais, o que Esser atribui crescente aproximação dos standards sociai e às idéias de valor subjacentes a cada ordenamento 90

$\mathrm{Na}$ Europa comunitária o Tribunal supranacional e a Arbitragem Internaciona desempenham relevantíssimo papel no que tange à formulação e consolidação de princípios unitários. A realidade do Mercosul diversa; contudo, a relativa similaridade do ordenamentos jurídicos do Brasil, Argentina, Uruguai e Paraguai - quanto mais não seja em razão de suas fontes históricas e de sua estrutura codificada - poderá tornar menos árdua a tarefa de harmonização do princípios e regras incidentes à fase pré-ne gocial dos contratos. Nesse sentido, a previsão, contida no Tratado de Assunção ${ }^{91}$, para que em novo tratado sejam postos os instrumentos necessários à sua estruturação poderia ensejar a elaboração de diretiva que, proveitando o fundo comum a essas tradições, consiga, harmonizando-as, conduzir à unificação das soluções na matéria.

Porto Alegre, setembro de 1992.

Notas

Ver, entre outros, René David, "Il Diritto del Commer. cio Internazionale: un nuovo compito per i legislatori nazio nali o una nuova lex mercatoria?". In Riv. Dir. Civ. Parte Prima, 1976, p. 577.

2 Para estas observações ver Bruno Oppetit, Autor du Contrat International, in Droits, 12, 1990, pp. 107 e ss. 3 idem, p. 108.

${ }^{4}$ Ver, nesta matéria, o ensinamento de Pontes de Miranda. Quanto às categorias da proposta e da aceitação, Tratado de Direito Privado, Tomos III e XXXVIII. Ver igualmente Clóvis do Couto e Silva, Para uma História dos Conceitos no Direito Civil e no Direito Processual Civil a Atualidade do Pensamento de Otto Karlovea e de Oskar Bullow, in Rev. de Proc. vol. 37, pp. 238 e ss., em especial p. 250 no que concerne à elaboração

do negócio jurídico e sua configuração atual. o que sucede nos contratos de engineering, nos
contracts to make contract que antecedem os financiamentos internacionais, nos de fornecimento de mate rias-primas e de tecnologia, só para citar alguns dos exemplos mais corriqueiros.

6 A expressão é de Mario Julio de Almeida Costa Direito das Obrigą̧ốes, Livr

7 In "Le Comada 'Indiniduel' et sa Définition". Ver Rev. Int Dr. Comp., 1988, pp. 327 e ss.

8 idem, p. 334

9 idem, ibidem. Ver, igualmente, Konrad Sweigert, "Du Sérieux de la Promesse", Riv. Int. Dr. Com. 1964, pp. 33 e ss.

${ }^{10}$ Em linhas gerais estes traços demarcariam a mais ampla definição de contrato passivel de ser deduzida ampla defhiçao de contrato passivel de ser deduzis Para o exa dis diferentes definições ver Guido Alpa op. cit., pp. 329 e ss.

Mesmo assim, houveram, no passado, pensadores, como Hugo Grotius, que perceberam nas promessas uma estrutura escalonada: no primeiro escalao estaria comunicaçăo de mero plano futuro de atuaçăo; no segundo, a "declaração-compromisso" de comportamento futuro, ou pollicialio, no terceiro, a decisa voluntária de transferência, para outrem, de un direlto. O fundamento da vinculabilidade das promessas residira no proprio p"opone tire natul". Näo por acaso recon hecida como un "dircilo fundamentos do conceito 
de direito subjetivo. (Ver Menezes Cordeiro, "Da Boa-Fé no Direito Civil", vol. I, Almendina, Coimbra, 1984, p 216 e Francesco Calasso, "Il Negozio Jurídico"'", Giuffrè,
Milăo, 1959, pp. 281 e ss).

12 Da copiosa bibliografia sobre o tema ver, no concernente à formação histórica, Alfred Rieg, "Le Rôle de la Volonté dans la Formation de l'Acte Juridique d'aprés Phes doctrines allemandes di XIXéme Siecle", Archives de
Philisophie du Droit, 1957, p. 2 e o meu estudo "Crise e Modificasaão da Nosáa de Contrato no Direito Brasileiro", Revista Direito do Consumidor, vol. 3, São Paulo, Editora Revista dos Tribunais, 1992; na bibliografia brasileira atualizada, Clóvis do Couto e Silva, "Para uma História dos Conceitos no Direito Civil e no Direito Processual Civil - A Atualidade do Pensamento de Otto Karlowea e de Oskar Bullowe", cit., supra, em especial no que concerne as observaçes acerca dos diferentes graus de valorizaçăo do ordenamento jurídico aos atos do particulares; do mesmo autor ver " $A$ Obrigagão como Processo", pp. 84 a 88 .

13 Por todos, Emilio Betti, "Teoria Geral do Negócio Jurídico", vol. I, trad. de Fernando de Miranda, Coimbra, 1969 .

14 Vide, além dos autores citados, as referências con signadas por José Carlos Moreira Alves, em especial em "A Parte Geral do Projeto do Código Civil Brasileiro", São Paulo, 1986, p. 99, nota ao pé da página.

15 Cf. Pontes de Miranda, "Tratado", cit. Tomo III Todavia, assinala Clóvis do Couto e Silva não ser importante o modo como se exterioriza a vontade, "se através de declaraşão ou de fato concludente", porquanto está superado, hoje, "o entendimento daqueles que exigiam. para caracterizar o negocio jurídico, a declarasaáo de vonta de", embora a necessidade da caracterização de "vontade
claramente exteriorizada, perceptivel, inequivoca" (Ver " $A$ claramente exteriorizada, perceptivel, in
Obrigasăo como Processo", cit. p. 202).

16 "O negócio jurídico bilateral solda dois negócios jurídicos que se destinavalm a isto (oferta, aceitaşa a). Por isto ba efeitos próprios, típicos, da bilalteralidade do negócio" (Pontes de Miranda, op. cit., parágrafo 278, 4).

17 idem, parágrafos $278,5,282,1$

18 idem, parágrafo $282,1$.

${ }^{19}$ Visualize-se, por exemplo, o tempo $\mathrm{e}$ a complexidade que envolvem um contrato de compra e venda de aeronaves para ter-se em conta as dificuldades de ser alcançado de imediato um acordo sobre todos os pontos objeto do negócio. Assim, também, a compra venda de petróleo, ou as cadeias de contratos por veze ocorrentes na exportação de alimentos.

20 As cartas que compõem essa correspondência são conhecidas sob o nome de intent letters, nos países da common lavw; lettres d'intention no direito francês, lettere di intenzione na Itália.

${ }^{21}$ No direito continental europeu essa acep̧ão é concebida como "minuta" ou "punctação".

22 Ver Guido Alpa, "Le Contrat 'Individuel' et sa Défini tion", cit., p. 338. Os dois primeiros sentidos do termo, acima indicados, caracterizam verdadeiras cartas de intenção; o terceiro, como visto, aproxima-se da punc tação, a qual se assemelha ao contrato preliminar $\mathbf{e} o$ quarto concerne ao caráter exaustivo do conteúdo do acordo, delineando propriamente um contrato. ${ }^{23}$ Nesse sentido, Fernando Pessoa Jorge, "A Formaşão
do Contrato d Face do Novo Código Civil Português", Revista Forense vol 294, pp. 56.

24 Vide, na doutrina brasileira, o excelente estudo de Walmor Francke, "Notas sobre o Pré-Contrato", in Revista Jurídica no 49 , p. 49 ei ss.

${ }^{25}$ Talvez o ordenamento jurídico que melhor tenha desenvolvido o instituto seja o alemão, que tipificou o Vorvertrag como o contrato que contém a obrigação de concluir um outro, de sorte que, segundo a célebre formulaçao de Degenkolb, "a obrigaşáo derivante do contrato preliminar será o encontro de declaraģôes de von cade que se completarao reciprocamente sobre um itinerário determinado". Consoante o BGB, o Vorvertrag é considerado "promessa obrigatoria" com a unica particula ridade de a obrigaçăo vir estabelecida por meio do parágrafo 894 ZPO. (Para estas observaçôes, consultei Renato Speciale, "Il Vorvertrag nell ambilo delle contrat to, in Riv. dir. civ., 1986, Parte Prima, pp. 45 e ss). Outros ordenamentos consignam a regra de a promessa so adquirir ficacia quando conter todos os elementos do futuro contrato: assim, ho direito anglo-amer cano ocorre a necessidade da consideration, e no direito continental europeu - especialmente na França e na lthia, adota-se oxame da causa. Em tema de direito comparado, no entanto, o essencial é atentar para o Isto porque, como bem adverte Guido Alpa, o que na Ito porque, como bem adverte Guido $\mathrm{Alpa}$, o que na de conside co comple e perfito, muitas vezs, na common la corresponde a figuras diversas, proximas da ideia de Alemare alen do mas, observa se a tendencia a fuga do Vorveruag, to mais, observase a tendência d̀ fug do Vorverrag, tido como demasiadamente vinculativo em contra parta novas figuras que permita do

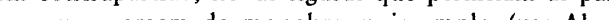

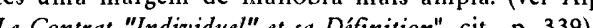

${ }^{26}$ Para o exame, no direito francês, da natureza da responsabilidade decorrente da realização de contrato preliminares, destinados à preparar o contrato definitivo, ver Joanna Schmidt-Szalewki, La Période Précontractuelle en Droit Fransais, Revue Internationale de Droit Comparé, 2, 1990, p. 545, em especial p. 555. 27 Vide RE $\mathrm{n}^{\circ} 88.716 \cdot \mathrm{RJ}$, STF, $2^{\mathrm{a}}$ T., Rel. Min. Moreira Alves, publicado in RTJ vol. 92, pp. 250 e ss, onde estabelecida a distinção entre "minuta" ou "protocolo de intençōes" e pré-contrato, firmando-se a orientação de ser essencial ao contrato preliminar que contenha "todos os elementos do contrato definitivo (...) não obrigando o mero acordo preliminar que não contemple vontade de se obrigar". No mesmo acórdão, contudo, votou vencido o Ministro João Leitāo de Abreu, que conferia à espécie interpretaçào mais flexivel, acolhen- do a tese de tratar-se, o caso examinado, de verdadeiro contrato preliminar, em razão da determinabilidade real e/ou potencial das cláusulas essenciais (ver, em especial, pp. 298 e ss.)

${ }^{28}$ Conforme Guido Alpa, op. cit., p. 334.

${ }^{29}$ Kings Bench Division (1923) ZKB 261, apud Guido Alpa, op cit. p. 335 .

${ }^{30}$ Assim Oppetit, op. cit., p.109.

${ }^{31}$ Nesse sentido Mario Bessone, Unilateral Mistake e Teoria del Contratto nell a esperienza nord-americana, in Rivista del Diritto Commerciale, 1970, pp. 248 e ss., em especial p. 252

32 Conforme Joseph Esser, Principio y Norma en la Elaboración Jurisprudencial del Derecho, trad. de Eduardo Valenti Fiol, Barcelona, 1961, p. 42, F. Kessler e E. Fine, Culpa in Contrabendo in Good Faith, and Freedo of Contract: A Comparative Study, in Harward Law R view, 77, 3, p. 401 e D.K. Allen, Pré-Contractual Liablity. Segundo esse autor a estoppel é em geral vista como uma "rule of evidence tbougth it bas substantive elements as weell. Existem diferentes modalidades, como a estoppel by representation, a promissory estoppel e a proprietary estoppel. (ver. pp. 93 e 94).

33 Conforme Jean Thieffy, Les nouvelles régles de là vent internationale, in Droit et Pratique du Commerce Interinternationale, in Droit et Prational, 15, 3, 1989, p. 377.

34 Sobre a comparação entre as noções de causa e consideration, ver Fabio Siebeneichler de Andrade, Cau sa e Consideration, Revista Ajuris vol. 53, Porto Alegre, 1991, p. 276.

35 Vide o estudo de Giuseppe Benedetti, La Categoria Generale del Contratto, in Rivista di Diritto Civile, 6 , 1991, pp. 649 e ss., em especial pp. 683 e 684 onde abordada a técnica empregada pela Convenção de Viena de 1980 sobre a compra e venda internacional, a qual, como é sabido, não apresenta definições exaustivas nem tipifica os institutos que regula, deixando margem, em sua aplicação, a um raciocinio de tipo problemático e năo sistematico. Ainda sobre a técnica utilizada na Convenção, Jean Theffry, op. cit., p. 375 e Philippe Kahn, Convention de Vienne du 11 avril 1980. Caractéres et domaine d'aplication, mesma revista, pp. 385 e ss.

36 Exemplo deste tratamento é dado por acórdão da Câmara de Comércio Internacional francesa datado de 1989 ("affaire 5904") assim ementado: Détermination de la loi applicable - Choix des parties dans le contrat limité a des dispositions nationales administratives. - Systeme de droit incomplet. Accord des parties pour l'application des principes et usages généraux el normaux du commerce international. - Lex mercatoria, complément de la loi du contrat. - Application du droit frangais à la détermination du taux d'intérels. - Lex fuori. - Obligation principale en franc fransais. (in Journal du Droit International, 1989, II, p. 1107). 37 op. cit. p. 112.

${ }^{38}$ Guido Alpa, op. cit., p. 337. Refere o autor exaustiva pesquisa comandada por S. Macaulay (Non-Contractual
Relations in Business: a preliminary Study", 28 Am. Sic. Rev., 1963, pp. 55 e ss.) a qual "avait remarqué la disparition du formalisme dan les rappots contractuels entre chefs d'enterprise, la planification progressive des rapports même entre entreprises, la survie de praxis enracinées, fondées sur la bonne foi et sur la correction "porquanto "les bommes d'affaires préferent souvent se reposer sur la parole de gentilbomme dans une courte lettre, avec une poignée de main, sur la "commune bonnêteté", même quand la négotiation comporte des risques consistants".

39 Ver, em especial, Clóvis do Couto e Silva, A Obrigasão como Processo, cit., pp. 29 e ss. e $O$ Princípio da BoaBrasileiro e Português, in Estudos de Direito Civil Brasileiro e Português, Editora Revista dos Tribunais, São Paulo, 1980.

40 Assim a disposição do art. $7^{\circ}$ segundo o qual "pour linterpretation de la présente Convention, il será tenu compde son caractere international et de la necessité de promouvoir l'uniformité de so apllication, ainsi que d'assurer le respect

(grifei).

${ }^{41}$ Ver Pontes de Miranda, Tratado de Direito Privado, Tomo IV

${ }^{42}$ Utilizo esta expressão como contraponto à idéia de eficácia plena, onde a totalidade das possibilidades de graduação estão preenchidas. Na "eficácia de primeiro grau" não se configuram todos os efeitos que podem ecorrer de um negócio, mas apenas parte deles, os quais se verificam na hipótese de lesão ao

${ }^{43}$ Assim, Clóvis do Couto e Silva, in Principes Fonda. mentaux de la Responsabilité Civile en Droit Brésilien et Comparé (Cours Fait à la Faculté de Droit et de Sciences Politigues de Saint Maur), Porto Alegre, 1988, datilografado.

44 Idem, pp. 9 e 10

${ }^{45}$ In A Responsabilidade Pré-Negocial pela não conclusão dos contratos, Boletim da Faculdade de Direito da Universidade de Coimbra, 1966, Supl. XIV, p. 151. Em relação ao direito civil alemão também Harm Peter Westermann acentua a tendência "a uma valoraşão justa dos interesses em um contato social", tendência que, no seu culpa in contrabendo. (ver Código Civil Alemão - Direito das Obrigasốes - Parte Geral, trad. de Armindo Edgar Laux, Sérgio Antonio Fabris Editor, Porto Alegre, 1983, p. 109.

46 Mota Pinto, op. cit., pp. 151 e 152

47 idem, ibidem.

48 Esta última expressão é utilizada por Clóvis do Couto e Silva. Ver O Princípio da Boa-Fé no Direito Brasileiro e Português, cit., p. 55.

${ }^{49}$ Ver Mario Julio de Almeida Costa, Aspectos Modernos do Direito das Obrigaşós, in Estudo de Direito Civil Brasileiro e Português, cit., p. 83. Lembrando que a doutrina das "relações contratuais de fato" está ainda
longe de obter consendo unânime refere o autor que 
"as melbores solusões que aconselbariam essa doutrina podem ser conseguidas, respectivamente: com base nos ditames da boaffe que presidem as negociaşoes e à formaşão do contrato, configurando a responsabilidade pré-contratual, que consa-
gra (no Projeto do Código Civil Brasileiro, art. 421) em termos expressos e amplos (...): e com apoio nos próprios princípios da ineficácia ou invalidade dos negócios jurídicos, enquanto se considerem suscetiveis de permitir, exxpcionalment

${ }^{50}$ Conforme Clóvis do Couto e Silva, $A$ Obrigaşão como Processo, cit., p. 12. Na doutrina estrangeira ver $\mathrm{K}$. Larenz, Derecho de Obligaciones, Tomo I, p. 37, como segue: "... entendemos la relación de obligación no solo como prestación aislada (crédito y deber de prestación), sino como la relación jurídica total (...).

51 Ver Clóvis do Couto e Silva, O Princípio da Boa-Fé no Direito Brasileiro e Português, cit., e $A$ Obrigasãa como Processo, em especial pp. 29 e ss. Também Ernesto Wayar, Derecho Civil - Obligaciones, Tomo I, Buenos Aires, 1990

52 Segundo Luiz Díez-Picazo "el deber jurídico es la necesidad en que la persona se encuentra de adoptar una determinada conducta o un cierto comportamiento en una están previstos como necesarios para el orden jurídico", encontrando-se a idéia de dever sempre conexionada à de responsabilidade. (in Sistema de Derecbo Civil, I, Madrid, 1990, p. 233). No que concerne aos deveres jurídicos que defluem do princípio da boa fé objetiva anota Clóvis do Couto e Silva que este, em relação ao direito das obrigaçōes - "manifesta-se como máxima objetiva gue delermina o aumento de deveres, além daqueles aue a convensão explicitamente constitui", operando, nos negócios bilaterais, "como mandamento de considerasãa" porquanto "o interesse conferido a cada participante da relasão jurídica (mea res agit ur) encontra sua fronteira nos interesses do oulro figurante, dignos de serem protegidos" (in A Obrigaşão como Processo, cit., pp. 29 e ss.).

53 Clóvis do Couto e Silva Principes Fondanentaux de

54 Atualmente a doutrina opõe-se à estreiteza da denominação culpa in contrabendo, porquanto o instituto não se limita aos fatos lesivos meramente culposos, podendo exigir-se o dolo e, como bem acentua Mario Julio de Almeida Costa, nem mesmo se circunscreve ds áreas da culpa em sentido lato, pois é possitiel a existéncia de respon. sabilidade pre-negocial objectiva, designadamente devida a fato de oultrem "(in Direito das Obriga gôes, cit. p. 236, nota

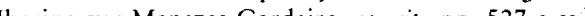

55 Responsabilitá Precontrattuale (Sintesi di Informazione), in Rivista di Diritto Civile, 1991, 6, Parte Prima, p. 729.

${ }^{56}$ Culpa in Contrabendo oder Scbadensersatz bei nicbtingen oder nicht zur Perfection gelangten Vertragen (in Jherings Iarbucher, 4, 1861, pp. 1 e ss. e in Gesammelte Aufsatze, I, Ierna, 1881, pp. 327 e ss. (Para estas referências consultei F. Benatti, A Responsabilidade Pré-Contratual, trad. de $\Lambda$. Vera Jardim e Miguel Caeiro, Coimbra,
68 Para o exame dos diferentes sistemas europeus ver Mario Bessone, Rapporto Precontrattuale e ainda Unilateral Mistake e Teoria del contratto nell'esperienza nord-americana, cit. e Menezes Cordeiro, op. cit., pp. 530 a 545.

${ }^{69}$ Assim Bessone, Rapporto precontrattuale, cit., p. 965.

70 Ver a arguta observação de Esser no que concerne à evolução da jurisprudência alemã sobre o tema (op. cit. pp. 209 a 211). Reportando-se ao mesmo tema, Menezes Cordeiro, op. cit., pp. 530 a 552.

71 op. cit., em especial pp. 412 e ss., onde anotado: "Modern contract lawe bas gone far in reconciling freedom of contract and the 'police of certainty' of transactions with the dictates of good faith and business convenience".

72 Nesse sentido, os parágrafos 1 - 203 do UCC ("obli. gation of good faitb in ... performance or enforcement) e 205 (RC) ("duty of good faitb and fair dealing in performance and enforcements), consoante anota. Allan Farnsworth in Negotiation of Contracts and Precontractual Liabilis Overbeck, Éditions Universitaires Fribourg, Suiça, 1990 , pverbeck, Editions Universi 65 , em especial p. 665 .

${ }^{73}$ Assim D.K. Allen, Pre-Contractual Liability, cit. p. 96

74 Assim os parágrafos 122, 123 e 307 do BGB que interpretados em consonância à cláusula geral da boa-fé do parágrafo 242 permitem aos juizes o controle sobre o comportamento observado no curso das tratativas.

75 Conforme Westermann, op. cit. p. 110, grifos do autor. Também Esser, op. cit., p. 210.

${ }^{76}$ Assim Harm Peter Westermann, op. cit., p. 127.

77 idem, p. 110

78 Afirma Bessoni que "la genericità della formula dell' art. 1337 e infatti il prezzo che la norma paga per assicurar al rinvio a buona fede il senso di una clausola generale operativa anche nella zona dei casi cbe la serie delle norm di specie lascia scoperta" (in Rapporto precontrattuale doveri di correttezza, cit., p. 983).

79 Conforme Joanna Schmidt-Szalewski, op. cit., p. 549 A "perte d'une chance não constitui uma certeza, mas uma probabilidade. Para obviar o requisito "certeza", essencial à configuração da responsabilidade civil, urisprudência entende que o prejudicado deve prova que existia uma probabilice raisonnable pour la réalisation de la cbance, considerando-se, ainda, o grau de avanço das tratativas para decidir "si la perspective de gain mérite d'être au moins partiellement prise en consid ration pour évaluer lindemnite". Ver, da mesma autora, La Sanction de la Faute Précontractuelle, in Revue Trimestrelle de Droit Civil, 1976, pp. 46 e ss.

80 "Quem negocia com outrem para a conclusão de um ontralo dene, tanto nos prelininares como na formaga

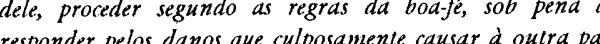
responder pelos dánes que culposamente causar a outra parto e Silva, O Princípio da Boa-Fé no Direito Brasileiro Porumb, 0 Prin 66 e 67 e de Mario Julio de Almeida Costa, Direito das Obrigasôes, cit. p. 240 e ss.
${ }^{81}$ Conforme Mario Julio de Almeida Costa, Direito das Obrigagõess, cit., pp. 237 e 238.

82 idem, p. 238, grifos meus.

83 Decisāo de 25.12.1986, Sala G, in Jurisprudencia Ar gentina, 1986, III, Sínteses, tradução e grifos meus.

84 in Contratos Ciniles y Comerciales - Parte General y Especial, Editorial Astra, Buenos Aires, 1990, p. 27. Também comentando a importância do princípio, Luis Andorno e Roque Garrido, in Reformas al Codigo Civil, Buenos Aires, $2^{2}$ edição, 1971, em especial pp. 310 e ss. 85 Veja-se ainda Ernesto Wayar, in Derecbo Civil - Obli. gaciones, Edicciones Depalma, Buenos Aires, 1990, em gaciones, , dicciones
especial pp. 27 e ss.

${ }^{86}$ Carlos Alberto Ghersi, op. cit., p. 28 (traduzi).

87 O Projeto de Código Civil contém, no art. 421 , disposição específica.

${ }^{88}$ Ver Clóvis do Couto e Silva, Principes Fondamentales de la Responsabilité Civile en Droit Brésilien et Comparé, cit., e Almiro do Couto e Silva, Responsabilidade do Estado e Problemas Jurídicos Decorrentes do Planejamento tora Revista dos Tribunais, pp. 29 e ss.

${ }^{89}$ Assim o magistério do STF in RTJ 13, p. 278

90 op. cit. p. 426.

$91 \mathrm{O}$ "Tratado para a Constituigão de um Mercado Comum entre a República Argentina, a República Federativa do Brasil, a República do Paraguai e a República Oriental do Uruguai" foi assinado em Asunción em 26 de março de 1991, entrando em vigor em novembro daquele mesmo ano. Estabelece, prioritariamente, propostas, princípios e instume pros para a contituica de um mercapios e instrumentos para a constituição de um mercá es cor estre os Estados signatários, o qual dever denominará "Mercado Comum do Sul" - MERCOSUL Os compromissos assumidos entre os Estados-parte implicam a "livre circulasáa de bens, servicos e fatores implicam a "livre circulasãa de bens, servilgos e fatores produtivos entre os paisse", no estabelecimento de tarifas comum em relação a terceiros Estados, bem como a coordenação de posiçōes em foros económicos comercoordenação de posiçoes em foros economicos regionais e internacionais, a coordeną̧ão de políticas macroeconômicas e setoriais e ainda o compromisso, dos Estados-parte, de barmonizar as suas legislaģóes nas áreas pertinentes para lograr o fortalecimento do processo de integraçăo. (Capítulo I, art. 10).

\section{Bibliografia}

Allen, D.K. Pre-Contractual Liability, in United Kingdom Comparative and Common Law - Studies for the XIIIth International Congres of Comparative Law, vol. 10, Londres, 1990, p. 90

Almeida Costa, Mario Julio. Aspectos Modernos do Direito das Obrigasões, in Estudos de Direito Civil Brasi-
66 Ver Menezes Cordeiro, op. cit., p. 13.

Assim, Mario Júlio de Almeida Costa, Direito das Obrigasôes, cit. p. 239. 
leiro e Português, Editora Revista dos Tribunais, São Paulo, 1986.

- . Direito das Obrigasôes. Livraria Almendina, Coimbra, 1991.

Andorno, L. e Garrido, R. Reformas al Codigo Civil. Buenos Aires, 1971, 2 edição.

Alpa, Guido. Le Contrat 'individuel' et sa définition, in Revue Internationale de Droit Comparé, 1988, p. 327.

Arietti, Marina. Responsabilitá Precontrattuale (Sintesi di Informazione), in Rivista di Diritto Civile, 1991, 6 p. 729.

Benatti, F. A Responsabilidade Pré-Contratual, trad. de A. Veras Jardim e Miguel Caeiro, Coimbra, 1970.

Benedetti, Giuseppe. La Categoria Generale del Contratto in Revista di Diritto Civile, 6, 1991, p. 649.

Bessone, Mario. Rapporto precontrattuale e doveri di correttezza, in Rivista Trimestrale de Diritto e Procedura Civile, 1972, p. 962.

-. Unilateral Mistake e Teoria del Contratto nell'esperienza Nord-americana, in Rivista di Diritto Commerciale 1970, 1, p. 248.

Betti, Emilio. Teoria Geral do Negócio Jurídico, trad. de Fernando de Miranda, Coimbra, 1969.

Calasso, Francesco. Il Negozio Giurídico. Giuffrè Editore, Milão, 1959

Couto e Silva, Almiro. Responsabilidade do Estado e Pro blemas Jurídicos Decorrentes do Planejamento, in Revista de Direito Público 65, p. 29, Editora Revista do Tribunais, São Paulo.

Couto e Silva, Clóvis. Para uma História dos Conceitos em Direito Civil e em Direito Processual Civil. a atualidade do pensamento de Otto Karlozera e de Oskar Bullow, in Revista de Processo, 37, p. 238.

-.A Obrigasão como Processo. José Bushatski Editor, São Paulo, 1976.

-. O Princípio da Boa.Fé no Direito Brasileiro e Português, in Estudos de Direito Civil Brasileiro e Português, Editora Revista dos Tribunais, São Paulo, 1986.

- Principés Fondamentaux de la Responsabilité Civile en Droit Brésilien et Comparé (Cours fait à la Faculté de Droit e de Sciences Politiques de St. Maur), Porto Alegre, 1988, datilografado.

David, René. Il Diritto del Commercio Internazionale: un nuovo compito per i legislatori nazionali o una nuova lex mercatoria? In Rivista di Diritto Civile, 1976 Parte Prima, p. 577.

Diez Picazo, Luis. Sistema de Derecho Civil, Tomo I, Madri, 1990.

Esser, Joseph. Principio y Norma en la Elaboración Jurisprudencial del Derecbo. Tradução de Eduardo Valenti Fiol, Barcelona, 1961 arnsworth, E. Allan. Negotiation of Contracts and Pre contractual Liabily: General Report, in Mélanges en l'honneur d'Alfred E. von Overbeck, Éditions Universitaires Fribourg, Friburgo, 1990, p. 747.

Francke, Walmor. Notas sobre o Pré-Contrato, in Revist Jurídica, 49, p. 49.

Ghersi, Carlos Alberto. Contratos Civiles y Comerciales Parte General y Especial. Editorial Astrea, Buenos Aires, 1990.

Jorge, Fernando Pessoa. A Formaşão do Contrato à face do Novo Código Civil Português, in Revista Forense, 294, p. 56.

Kahn, Philipe. Convention de Viene du 11 avril 1980 Caracteres et Domaine d'Aplication, in Droit Interna tional, 2, Commerce International, 15, 3, 1989, p. 385.

- Les principes généraux $d u$ droit devant les arbitres $d u$ commerce international, in Journal du Droit International, 2, 1989, p. 305.

Kessler, $\mathrm{F}$ e Fine, Edit. Culpa in Contrabendo, Bargaining in Good Faith and Freedom of Contract: A Comparative Study, in Harward Law Review, 1977, p. 401.

Larenz, Karl. Derecho de Obligaciones, Tomo I, trad. esp. de Jaime Santos Briz, Editorial Revista de Derecho Privado, Madrid, 1958.

Martins-Costa, Judith. Crise e Modificaşãa da Nosão de Contrato no Direito Brasileiro, in Revista Direito do Consumidor, 3, São Paulo, 1992

Menezes Cordeiro, A. M. Da Boa Fé no Direito Civil Livraria Almendina, Coimbra, 1986.

Moreira Alves, José Carlos. A Parte Geral do Projeto do Código Civil Brasileiro, São Paulo, Editora Revista dos Tribunais, 1986.

Mota Pinto, Carlos Alberto. A Responsabilidade Pré-Ne gocial pela não conclusão dos contratos, in Boletim da Faculdade de Direito da Universidade de Coimbra, 1966, Supl. XIV.

Oppetit, Bruno. Autour du contrat international, in Droits, 12, 1990, p. 107

Pontes de Miranda. Tratado de Direito Privado, Tomos III, IV e XXXVIII

Schmidt-Szalewski, Joanna. La Période Précontractuelle en Droit Frangais, in Revue Internationale de Droit Comparé, 2, 1990, p. 545.

Speciale, Renato. Il Vorvertrag nell'ambito delle contratto in Revista di Diritto Civile, 1986, Parte Prima, p.

Thieffy, Jean. Les nouvelles règles de la vente internationa le, in Droit et Pratique du Commerce International, 15, 3, 1989, p. 369.

Wayar, Ernesto. Derecho Civil. Obligaciones, Tomo I Editorial Depalma, Buenos Aires, 1990
Wengler, Wilhelm. Les principes généraux du droit en tan que loi du contrat, in Revue Critique du Droit International Privé, 1982, p. 17.

Westermann, Harm Peter. Código Civil Alemão - Direito da
Obrigąõos - Parte Geral, trad. de Armindo Edgar Laux, Sergio Antonio Fabris Editor, Porto Alegre, 1983.

Zweigert, Konrad. Du Sérieux de la Promesse, in Revue 